\title{
Exploiting Experience-Dependent Plasticity in Dysphagia Rehabilitation: Current Evidence and Future Directions
}

\author{
Phoebe Macrae • Ianessa Humbert
}

Published online: 17 September 2013

(C) Springer Science + Business Media New York 2013

\begin{abstract}
Experience-dependent plasticity (EDP) is a general term used to describe neural and associated behavioral adaptations resulting from experience. Because the objective of dysphagia rehabilitation is to induce longterm permanent change in swallowing physiology, understanding EDP processes is crucial for documenting the efficacy of treatments. There is little information about natural processes of EDP related to swallowing (i.e., changes associated with aging and impairment). Therefore, the "baseline" on which we apply dysphagia treatments remains unclear. Because EDP is characterized by peripheral and central adaptations of physiologic and functional measures over time, effectively documenting EDP requires multiple outcome measures at multiple time points. This review will discuss mechanisms of endogenously induced EDP, including aging and impairment. A review of current dysphagia rehabilitation literature will be provided to indicate the state of evidence for exogenously induced EDP. Future considerations for the study of EDP related to dysphagia will also be offered.
\end{abstract}

Keywords Swallowing - Dysphagia - Deglutition · Plasticity $\cdot$ Rehabilitation

\section{Introduction: What is Experience-Dependent Plasticity?}

Experience-dependent plasticity (EDP), sometimes used interchangeably with experience-dependent learning, is a

P. Macrae $(\bowtie) \cdot$ I. Humbert

Department of Physical Medicine and Rehabilitation, School

of Medicine, Johns Hopkins University, 98 N Broadway,

Baltimore, MD 21231, USA

e-mail: pmacrae1@jhmi.edu broad term referring to changes of neural and behavior networks in response to experience. "Experience" can be characterized by physiological mechanisms, including impairment, and environmental influences [1••]. These changes can be short-term (i.e. adapting to a temporary oral appliance) or long-term (i.e. adapting to a partial glossectomy). Our understanding of the impact of environmental effects on plasticity has deepened with manifold evidence that neuroplasticity occurs over the lifespan of normally developing humans, long after critical developmental periods of infancy and childhood [1••]. EDP is particularly interesting in adults, because it can be manipulated through research to understand the underlying mechanisms in multiple sensorimotor systems. In some medical disciplines, EDP is regarded as an essential part of clinical intervention and research, for providing insight into the course of recovery from impairment. Specifically, the field of rehabilitation is coming to terms with the magnitude of EDP, both in terms of naturally occurring, or endogenous $E D P$, and externally induced, or exogenous EDP. Endogenously induced EDP can include phenomena such as normal aging (i.e. gradually adapting to weakening muscles or weight changes) and impairment (i.e. stroke or neurodegeneration). Exogenously induced EDP involves the manipulation of experiences and environments to induce learning and plasticity processes. The most complex hurdle in characterizing EDP is understanding how multiple, co-occurring forms of EDP interact and affect functional outcomes [2*0]. The importance of considering plasticity in the arena of swallowing research and clinical rehabilitation of dysphagia has been introduced in recent publications [3, 4]. The purpose of this review is to provide an update on how studies to date have addressed this area of EDP associated with healthy and disordered swallowing, and dysphagia rehabilitation. 
Even for the most common and well-studied etiologies of dysphagia, we lack a sound understanding of the naturally occurring changes that result from the experience of impaired swallowing. This is largely because treating patients identified with dysphagia is rightfully a far greater priority than studying natural EDP processes. However, "the need to treat" has been determined without convincing evidence that exogenously induced EDP is superior to endogenously induced EDP. Determining the benefit of treatment over no treatment is restricted by a number of factors. First, the shortage of information on endogenously induced EDP associated with dysphagia means we cannot adequately characterize "normal response", or ascertain a true "baseline" of EDP. Second, the cross-effects of different EDP phenomena on swallowing behavior are not understood. For example, how one's experience of endogenously induced EDP (i.e., aging and impairment) influences their response to exogenously induced EDP (i.e., treatment). One is reminded to remain cognizant of the limited knowledge we have of natural aging and impairment as we discuss the processes of exogenously induced EDP, which are frequently overlaid on to endogenous experiences. Finally, we do not have sound evidence demonstrating how EDP is affected by dysphagia treatments [4]. The section on exogenously induced EDP will show that a large number of studies investigate components of this process. These components include when treatment effects are measured (during treatment versus post-treatment changes), and what outcome measures are utilized (physiological versus functional outcome measures). However, our understanding remains limited because many studies do not link these components to obtain a full picture of EDP processes. This review will provide an overview of how EDP is measured. The mechanisms of endogenously induced EDP will be discussed, including aging and impairment. A review of dysphagia rehabilitation literature will be provided to indicate the evidence available for characterizing EDP associated with current treatments. Future considerations for the study of EDP related to dysphagia will also be offered.

\section{Measuring Experience-Dependent Plasticity (EDP)}

One key component for examining EDP is time. In many studies that investigate the effect of experiences on plasticity or learning, a structure or function is examined over time to document the process of change. The duration of examination depends on the outcome variable that is being tested (i.e. hand movement versus neuronal growth) [2••]. Another important concept is that EDP manifests through central and peripheral nervous system (PNS) changes [1••], meaning simple observations of behavior may provide insight into plasticity mechanisms. It must be remembered that such observations only infer plasticity of neural processes considered necessary for lasting behavioral change. It is well known that behavioral changes may manifest in the absence of neural changes, i.e., through changes in muscle composition [5-8], or refined movement control resulting from repetitive practice [8]. Throughout this review, the distinction between physiological and functional measures of EDP is made. Swallowing-specific functional measures are defined as any of the following: measures of penetration or aspiration, estimates of residue, and quality of life indicators. This is based on the fact that changes in these measures in isolation can be definitively categorized as beneficial or detrimental to patient wellbeing. Peripheral physiologic measures are defined as temporal or spatial measures of various physiologic or kinematic events, for example tongue pressures and laryngeal vestibule closure duration, respectively. Changes in these measures alone cannot be deemed beneficial or detrimental to effective nutritional deglutition; thus, concurrent assessment of functional measures is needed. In other words, longer duration of laryngeal vestibule closure that is not accompanied by reduced aspiration does not necessarily reflect positive treatment outcomes. The principles of EDP propose that behavioral changes (i.e., functional and peripheral physiologic measures) associated with learning are accompanied by plasticity of the neural networks responsible for that behavior [2••]. We define such neural changes as central physiologic measures, involving the brain and corticobulbar projections, but not the peripheral structures. In the case of injury to the PNS, it is known that axons are capable of regeneration (i.e., plasticity). However, PNS plasticity in the absence of CNS plasticity is unlikely to result in functional recovery [9]. Peripheral nerves have been studied in swallowing only as a vehicle for inducing CNS plasticity $[10,11]$, rather than for documenting the process of PNS plasticity. Because the PNS is most frequently discussed as the means by which central adaptations are communicated, plasticity specific to the PNS is not included in this discussion of neural plasticity.

When studies attempt to link changes in physiologic outcomes to functional outcome measures, this provides a unique opportunity to evaluate the effect of physiological change on meaningful swallowing measures. Thus, when studies document changes in physiologic measures but find no concurrent changes in functional measures, this relationship must be called into question. A lack of change in functional measures suggests one or more of the following:

1 the measure of function is not sensitive to changes in relevant physiology;

2 the physiologic measures chosen are not crucial to the functional outcome being tested; or

3 more than one physiologic process gives rise to the functional outcome of interest, i.e., detecting a 1:1 
change requires measurement of multiple physiologic processes.

Peripheral EDP is defined as change in peripheral structure or function, for example muscle physiology or kinematics. As mentioned above, PNS plasticity is not included in this definition. Central EDP involves adaptations of the central nervous system. Despite the interdependence of central and peripheral adaptations in EDP, these processes are frequently investigated in isolation. As mentioned above, simple observations of behavior are often used to infer the presence of responsible central EDP mechanisms. Therefore, the dichotomy between central and peripheral EDP is made for facilitating the review of studies that aim to investigate only one of these components. Peripheral EDP associated with swallowing has been measured with a number of tools, including videofluoroscopy (VFS), fibreoptic endoscopic evaluation of swallowing (FEES), pharyngeal manometry, oral pressure sensors, surface electromyography (sEMG), magnetic resonance imaging (MRI), and ultrasound. Central EDP has been documented using measures of neural activation and cortical excitability, made with techniques such as functional magnetic resonance imaging (fMRI), magnetoencephalography (MEG), and motor evoked potentials (MEPs) induced with transcranial magnetic stimulation (TMS).

\section{Aging and Endogenously Induced Experience- Dependent Plasticity}

Development clearly plays a critical role in EDP. The most widely understood developmental stage is the critical period of plasticity in early development [12-15]. However, there is evidence that central and peripheral EDP processes occur well into adulthood $[1 \bullet \cdot, 16]$. Aging as a form of EDP has been examined through cognitive, sensory, and motor task training [17, 18]. Compensatory mechanisms as a means of adapting to senescence have also been reported for various sensorimotor systems $[19,20]$. Inherent in the process of aging is exposure to a countless number of experiences. Experiences such as stress, diet, and tasklearning all have the ability to produce durable changes in neural networks $[2 \bullet \cdot$. A combination of these experiences is known to affect spontaneous recovery, and response to intervention [2••]. Therefore, the simple occurrence of life experience throughout the aging process predisposes the geriatric population to greater variability in their response to injury and recovery. Additional factors that may induce EDP over protracted periods of time during the aging process include reduced strength and endurance, as well as cognitive, social, and emotional experiences [19, 21-23]. Understanding these processes and how they relate to dysphagia recovery may provide insight into optimal treatment conditions for elderly patients.

In swallowing, aging has been examined in many research studies. Presbyphagia is a term used to refer to normal, age-related changes in the swallowing mechanism of otherwise healthy older adults [24]. Some age-related anatomical differences in structures involved in swallowing include smaller cross-sectional area of the tongue and atrophy of the thyroarytenoid muscles [25-27]. Sensory function of the oral cavity is also affected, with reduced spatial tactile perception of the lips and tongue, and deficiencies in stereognosis, taste, and viscosity in the oral cavity [28-32]. These anatomical and functional variations probably underlie kinematic changes that are characteristic of presbyphagia, including delayed initiation and slower kinematics of the pharyngeal swallow [24, 33-36]. Healthy older adults also report dysphagia symptoms more frequently than healthy young adults, including coughing and food sticking in the throat [37]. fMRI studies of the brain have reported both decreased and increased blood-oxygenlevel-dependent (BOLD) signals in healthy older adults compared to young adults for swallowing tasks, indicating that age-related neurophysiologic changes in swallowing are also evident [38-42].

Despite these established age-related changes in swallowing function, few studies have investigated how the factors associated with age affect the presence and recovery of dysphagia. Studies of overall motor function suggest that while outcomes at discharge may be worse for older patients after stroke [43, 44], the amount of improvement from admission to discharge does not differ with regards to age $[44,45]$. Similarly, studies have documented increased age as a predictor of poorer outcomes related to persistence of dysphagia [46, 47], but improvements from admission to discharge are not determined by age [48, 49]. Functional abilities on admission are lower in the geriatric population because of factors associated with age [45], suggesting that age in and of itself should not be considered prognostic of poor functional outcomes. Further research is needed to identify the factors associated with age that are more likely to result in poor outcomes for dysphagia recovery. Research is also required to determine which of those factors are more (or less) amenable to therapy.

\section{Dysphagia and Endogenously Induced Experience- Dependent Plasticity}

Dysphagia itself is a symptom of an array of disorders, affecting individuals across the lifespan. Because of the multitude of medical diagnoses associated with dysphagia, it is an immense task to document the changes typical of each disorder, let alone the natural response of individuals 
to such changes. There are well-documented degenerative and regenerative processes that occur implicitly with injury, for example edema, cell death, and regeneration [2॰.]. The term "natural response" denotes adaptations or learning associated with the experience of disorder, and therefore incorporates processes that both facilitate and hinder recovery. It is known that these adaptations, in the absence of intervention, occur in both peripheral and central systems [50, 51].

Peripheral response to injury manifests as compensatory behavioral changes that develop from learning to facilitate function in the face of impairment [51, 52]. Animal research suggests that restoration of functional movement is largely a result of these compensatory movements, with motor training (or exogenously induced EDP) having a minimal effect $[50,52]$; in other words, motor training may only provide a forum in which self-taught compensatory behaviors can develop. The findings that these natural behavioral responses are tightly linked to neural plastic adaptations [53] and functional recovery $[50,52]$ reveal the importance of characterizing this natural compensatory behavior. Evidence of self-taught compensatory behaviors in dysphagic patients has previously been reported by Kahrilas et al. [54], and is certainly frequent in clinical anecdote. Endogenous learning during impairment can also induce maladaptive behavior [50], further reinforcing the importance of understanding natural response. It is known that in the field of speech production, self-taught articulation patterns that develop during cleft palate can be persistent after corrective surgery [55]. Increased time spent using these compensatory patterns before surgery increases the chance they will persist [56]. Therefore, spontaneous recovery not only provides a window of opportunity for beneficial compensatory strategies to develop, but may also render maladaptive behavior resistant to therapy. While clinical anecdote suggests maladaptive self-taught swallowing behaviors can develop in the absence of intervention, as far as we are aware, research describing such behaviors does not exist.

Two studies have investigated central adaptations that occur in association with acquired dysphagia [57, 58]. These studies documented neural correlates of behavioral changes associated with natural recovery from dysphagia. Observed increases in somatosensory cortex activation [58] and increased cortical representation of target muscles [57] were associated with improved functional outcomes, measured using VFS [57] and FEES [58]. These functional assessments are an important aspect of EDP studies, as neurophysiologic measures alone do not reflect peripheral physiology or functional outcomes, and therefore do not provide a direct measure of swallowing per se. Understanding the relationship between physiological and functional measures is crucial for interpretation of either. For example, it is tempting to view reduced cortical excitability (central physiology) as detrimental to swallowing function. However, if accompanied by an increase in oral intake, or reduced aspiration (functional outcome), reduced cortical excitability may be viewed as beneficial. Alternatively, such an outcome could also suggest that the central and peripheral measures do not have a direct relationship and perhaps some other neural measure is changing alongside the functional improvements.

As already stated, knowledge of endogenously induced EDP is important because it can affect therapeutic endeavor. An example of this is the tongue-hold maneuver. The maneuver was developed after the observation that some patients with presumed reduction in base of tongue retraction due to anterior tongue resection had a natural compensatory adaptation of posterior pharyngeal wall bulging during the swallow $[59,60]$. Therefore the technique was devised to mimic impairment, and replicate the effects of endogenous learning seen as a result. It should be noted, however, that simply replicating a natural EDP process as an intervention does not preclude the behavior from being maladaptive. Confirmation of positive functional gains alongside observations of increased posterior pharyngeal wall bulging is required to determine the benefit of such change. Furthermore, without confirmation of central adaptations associated with the technique, it remains unknown whether the peripheral modifications are reflective of lasting changes or merely represent altered muscle physiology or kinematics.

\section{Dysphagia Treatments and Exogenously Induced EDP}

The objective of dysphagia rehabilitation is to induce longterm permanent change in swallowing physiology. The relationship between environmental experience and EDP is well documented $[1 \bullet \bullet, 2 \bullet, 51,53,61,62]$, but how these phenomena can be positively affected by dysphagia intervention is not clearly understood [4]. Allred argues "It is not enough to know that experience matters" [50]. Because a multitude of experiences interact to affect EDP and functional outcomes [2••], we need to understand the relationships among the various processes before attributing benefit to intervention. This section focuses on factors that swallowing treatment studies should consider to maximize their observations of EDP.

Measuring Treatment Effects at Multiple Time Points is Required to Characterize EDP

To document relatively permanent changes in swallowing neurophysiology resulting from treatments, investigation of changes during and after extended duration of treatment is required. Much research effort in dysphagia management 
has been focused on documenting changes that occur during execution of treatment techniques, with fewer studies providing evidence of more permanent changes, i.e., pre and post-treatment designs. The terms "standard" and "traditional therapy" are frequently used in swallowing literature to refer to a combination of therapies, including effortful swallowing, Mendelsohn maneuver, tongue-hold technique, and Shaker exercise. Emerging treatments are those that are frequently compared to traditional treatment in the literature, including neuromuscular electrical stimulation (NMES), expiratory muscle strength training (EMST), lingual strengthening, and McNeill dysphagia therapy program (MDTP). Treatments are therefore dichotomized for this review according to these categorizations used frequently in the swallowing literature. When reviewing the literature, one will note that the traditional techniques have very few pre and post-treatment studies dedicated to documenting long-term learning and plasticity (Table 1). Studies that have investigated long-term treatment effects of these traditional treatments have typically combined multiple exercises into their treatment protocols [63-71], and therefore, positive (or negative) outcomes cannot be attributed to any one exercise.

This lack of long-term evidence for traditional therapy poses a problem for two reasons. First, traditional techniques are commonly prescribed for dysphagic patients, with very little understanding of their long-term effects. Second, the terms "traditional therapy" or "standard therapy" are repeatedly used in the scientific literature to describe control groups against which emerging therapies are evaluated, often to avoid the ethical limitation of not providing treatment. Furthermore, many studies combine traditional techniques with other treatments in their investigations. As the long-term effects of these traditional treatments on EDP are not well studied or understood, the condition used as a control for many emerging treatments is equally obscure. The last two years has seen the re-emergence of investigations into the effect of traditional therapies in isolation [72-74]. The increasing number of available treatments and the multiple etiologies and physiologic abnormalities associated with dysphagia make it is an immense task to document the long-term effects of all treatments. However, methodically filling these gaps in the literature is required to ensure that we not only provide adequate evidence to support robust treatments but also equip ourselves with sufficient evidence to exclude treatments that hold no promise of enhancing recovery from dysphagia.

In addition to pre and post-treatment measures, Humbert et al. [75, 76] highlight the important role of during-treatment measures in understanding the process of learning, or EDP resulting from swallowing treatment. Changes measured during treatment reflect performance of a task [77]. However, measures of performance cannot be presumed to reflect learning [77]. Learning is defined as "a relatively permanent change resulting from practice or experience" [78]. There is evidence to suggest that the conditions which induce the most desirable performance effects can be least effective in inducing desirable learning effects, and vice versa [78]. Therefore, measures obtained both during and following treatments are required to establish this relationship. Table 1 shows that although emerging therapies have improved on the number of pre and post-treatment studies compared with traditional therapies, there are still few investigations documenting performance effects. An additional important consideration is that both duringtreatment and post-treatment behaviors can gradually adapt over time, because of learning and recalibration of

Table 1 Common treatments used in dysphagia management

\begin{tabular}{|c|c|c|c|c|c|c|c|c|}
\hline \multirow[b]{2}{*}{$\begin{array}{l}\text { Emerging } \\
\text { treatments }\end{array}$} & \multicolumn{4}{|c|}{ During treatment effects (A) } & \multicolumn{4}{|c|}{ Pre and post-treatment effects (B) } \\
\hline & NMES & EMST & $\begin{array}{l}\text { Lingual } \\
\text { strengthening }\end{array}$ & MDTP & NMES & EMST & $\begin{array}{l}\text { Lingual } \\
\text { strengthening }\end{array}$ & MDTP \\
\hline $\begin{array}{l}\text { Physiologic } \\
\text { outcomes }\end{array}$ & [91-95] & [96-98] & $\begin{array}{l}{[89,90,99-} \\
102]\end{array}$ & & {$[92,103-113]$} & $\begin{array}{c}{[96,114} \\
115]\end{array}$ & $\begin{array}{r}{[89,90,99} \\
100,116]\end{array}$ & $\begin{array}{c}{[104,117,} \\
118]\end{array}$ \\
\hline $\begin{array}{l}\text { Functional } \\
\text { outcomes }\end{array}$ & {$[95]$} & & {$[89,90]$} & & $\begin{array}{c}{[103-107,109,111,} \\
112,119-130]\end{array}$ & {$[114,115]$} & $\begin{array}{l}{[89,90,99,} \\
100]\end{array}$ & $\begin{array}{l}{[104,117} \\
118,131]\end{array}$ \\
\hline $\begin{array}{l}\text { Traditional } \\
\text { treatments }\end{array}$ & $\begin{array}{l}\text { Effortful } \\
\text { swallowing }\end{array}$ & Mendelsohn & Tongue-hold & Shaker & $\begin{array}{l}\text { Effortful } \\
\text { swallowing }\end{array}$ & Mendelsohn & Tongue-hold & Shaker \\
\hline $\begin{array}{l}\text { Physiologic } \\
\text { outcomes }\end{array}$ & $\begin{array}{l}{[98,132-} \\
150]\end{array}$ & $\begin{array}{c}{[98,139,147,} \\
151-157]\end{array}$ & $\begin{array}{l}{[60,142,} \\
158-160]\end{array}$ & $\begin{array}{l}{[102,161-} \\
165]\end{array}$ & [110] & {$[72,73]$} & {$[74]$} & {$[165-170]$} \\
\hline $\begin{array}{l}\text { Functional } \\
\text { outcomes }\end{array}$ & {$[133,135]$} & {$[155]$} & & & & {$[72,73]$} & & {$[168,169]$} \\
\hline
\end{tabular}

Treatments are separated into emerging (above) and traditional (below). Studies have been categorized according to whether they provide "during-treatment" effects (A), or "post-treatment" effects (B) based on pre and post-treatment design. Studies have further been categorized according to whether they utilize peripheral physiologic outcome measures, or functional outcome measures 
movements [75, 76]. Many studies obtain only a small number of swallows at any given time point. Furthermore, these swallows are often averaged to reduce variance. It is therefore possible that gradual change associated with learning goes undetected. Some studies make assessments at multiple time points after completion of treatment to define the timeframe of treatment effects [79-88]. To characterize learning effects within each time point, observation of multiple, consecutive trials is required.

Table 1 shows there is a small number of studies for any given treatment, traditional or emerging, investigating both physiologic and functional outcome measures. A total of two studies in Table 1 document both physiological and functional outcomes during and after treatment [89, 90]. Although there is more physiologic and functional evidence for emerging treatments compared with traditional, examining the two in tandem is a process that remains uncommon. More studies making these connections are crucial if we are to understand how to promote EDP processes that result in meaningful change for patients with dysphagia.

Although investigations of rehabilitative strategies on peripheral physiology are emerging, research must expand to determine the neurophysiologic foundations of peripheral adaptations [171]. Most studies investigating central EDP associated with dysphagia treatments have utilized pre and post-treatment designs to assess long-term adaptations. Very few of these studies incorporate duringtreatment observations of central EDP processes. Similarly, studies looking at during-treatment effects have not extended their observations to post-treatment assessment. One study expanded their during-treatment observations to include multiple repetitions of each task, to investigate gradual changes in treatment response [172]. This fMRI study found the BOLD response increased with repeated exposure to heightened sensory experiences (visual biofeedback and sour bolus), while it decreased with repeated water swallows [172]. As highlighted by the authors, investigations of peripheral physiology and functional outcomes are required to determine the clinical relevance of these central EDP observations. There are few demonstrations of how peripheral physiology and functional outcomes relate to central EDP associated with treatments. Two studies have combined neurophysiologic measures with functional outcome measures to draw functional conclusions about central changes [109, 171]. Oh and colleagues report functional improvements in stroke patients after NMES. Despite the authors' claim that increased cortical maps accompanied these functional improvements, their measures of central physiology did not reach statistical significance [109]. Malandraki et al. report a case study of a stroke patient who underwent eight weeks of lingual exercise [171]. They observed increased activations in the primary motor and primary sensory cortex, and in the premotor area and the insula. Improved penetration and aspiration, reduced residue, and increased lingual pressures accompanied these central physiologic adaptations. Although the authors acknowledge the limitations of a single-subject design, it is interesting to note that aspects of their findings are similar to those reported for natural recovery [58]. The paucity of literature in this area highlights the need for more studies incorporating physiology and function, both during and after treatment periods. Only then can we gain a full picture of EDP processes associated with dysphagia treatments.

\section{Studying Healthy Participants to Document EDP}

Many would question the possibility of seeing EDP processes in healthy participants as a response to treatment. Numerous investigations of swallowing treatments show that healthy subjects are capable of demonstrating central $[10,11,80,82-88,172-177]$ and peripheral [89-92, 99, 100, 103, 104, 108-116, 126, 176] adaptations. The limitations in investigating endogenously induced EDP (discussed above) require researchers to develop innovative ways to glean this information. Investigating EDP that occurs as the healthy system learns, or compensates and corrects for errors, offers an alternative [178]. Perturbing the swallowing process of healthy participants or creating "pseudo-impairment", and observing the resulting change in physiologic and functional measures may provide useful information about the effect of, and response to, impairment. Healthy adults (young and old) are capable of safely responding to novel and unexpected circumstances [75, 76, 179]. The question of whether healthy participants are capable of demonstrating functional change depends on the criteria of "improvement" or "decline". An alternative approach is to document the magnitude of change without qualitative assumption of such adaptations. Findings should then be replicated in patient populations, from whom qualitative conclusions can be made alongside meaningful measures of functional change.

\section{Conclusions}

An increasing number of treatments is available for dysphagia management. Treatments have been developed with the purpose of inducing long-lasting change in swallowing neurophysiology, by promoting peripheral and central plasticity through experience. Our understanding of natural processes of EDP, such as age and injury, are limited. To provide a thorough evidence-base for dysphagia treatments, we require more information about these natural processes, and about how overlying exogenous EDP 
processes affect functional outcomes. The aging process, experience of injury, and the presence or absence of adaptive compensation may all be underlying factors contributing to variability among patients with a seemingly similar clinical history. Although natural EDP processes remain difficult to elucidate, focusing on the plasticity and learning capability of healthy subjects through studies that perturb swallowing will elucidate EDP processes related to "pseudo impairment". Many basic questions regarding many treatments still require attention before the more complex process of documenting efficacy in patients is justified. More thorough investigation of the long-term effects of traditional therapies is required if we are to continue to use these therapies as control conditions. Observations should be made during treatment periods, and on completion of treatment protocols to adequately characterize the process of EDP. Outcome measures must address both physiological and functional adaptations if clinical conclusions are to be drawn from such research. Only when we begin to adequately characterize these processes of EDP can we begin to deduce the functional superiority of dysphagia treatments over spontaneous recovery.

Acknowledgments This manuscript was prepared during the tenure of a Postgraduate Scholarship of the New Zealand Neurological Foundation awarded to Dr. Phoebe Macrae. NIH Grant: NIDCD 1K23DC010776-01, 2009-2014 awarded to Dr Ianessa Humbert.

\section{Compliance with Ethics Guidelines}

Conflict of Interest P. Macrae and I. Humbert have no conflict of interest to disclose.

Human and Animal Rights and Informed Consent This article does not contain any studies with human or animal subjects performed by any of the authors.

\section{References}

Papers of particular interest, published recently, have been highlighted as:

•- Of major importance

1. • Foscarin S, Rossi F, Carulli D. Influence of the environment on adult CNS plasticity and repair. Cell Tissue Res. 2012;349: 161-67.

2. • Kolb B, Teskey GC. Age, experience, injury, and the changing brain. Dev Psychobiol. 2010;54:311-25.

3. Martin RE. Neuroplasticity and swallowing. Dysphagia. 2009; 24:218-29.

4. Robbins J, Butler SG, Daniels SK, Gross RD, Langmore S, Lazarus CL, et al. Swallowing and dysphagia rehabilitation: translating principles of neural plasticity into clinically oriented evidence. J Speech Lang Hear Res. 2008;51:S276-300.
5. Esposito F, Ce E, Gobbo M, Veicsteinas A, Orizio C. Surface EMG and mechanomyogram disclose isokinetic training effects on quadriceps muscle in elderly people. Eur J Appl Physiol. 2005;94:549-57.

6. Folland JP, Williams AG. The adaptations to strength training: morphological and neurological contributions to increased strength. Sports Med. 2007;37:145-68.

7. Kanehisa H, Nagareda H, Kawakami Y, Akima H, Masani K, Kouzaki M, et al. Effects of equivolume isometric training programs comprising medium or high resistance on muscle size and strength. Eur J Appl Physiol. 2002;87:112-9.

8. Rasch PJ, Morehouse LE. Effect of static and dynamic exercises on muscular strength and hypertrophy. J Appl Physiol. 1957; 11:29-34.

9. Navarro X, Vivo M, Valero-Cabre A. Neural plasticity after peripheral nerve injury and regeneration. Prog Neurobiol. 2007;82:163-201.

10. Hamdy S, Aziz Q, Rothwell JC, Hobson A, Barlow J, Thompson DG. Cranial nerve modulation of human cortical swallowing motor pathways. Am J Physiol. 1997;272:G802-8.

11. Hamdy S, Aziz Q, Rothwell JC, Hobson A, Thompson DG. Sensorimotor modulation of human cortical swallowing pathways. J Physiol. 1998;506:857-66.

12. Hensch TK. Critical period plasticity in local cortical circuits. Nat Rev Neurosci. 2005;6:877-88.

13. Hensch TK. Critical period mechanisms in developing visual cortex. Curr Top Dev Biol. 2005;69:215-37.

14. Hensch TK, Fagiolini M. Excitatory-inhibitory balance and critical period plasticity in developing visual cortex. Prog Brain Res. 2005;147:115-24.

15. Hensch TK. Controlling the critical period. Neurosci Res. 2003;47:17-22.

16. Erickson KI, Colcombe SJ, Wadhwa R, Bherer L, Peterson MS, Scalf PE, et al. Training-induced plasticity in older adults: effects of training on hemispheric asymmetry. Neurobiol Aging. 2007;28:272-83.

17. Degen C, Schroder J. Training-induced cerebral changes in the elderly. Restor Neurol Neurosci. 2013.

18. Anderson S, White-Schwoch T, Parbery-Clark A, Kraus N. Reversal of age-related neural timing delays with training. Proc Natl Acad Sci USA. 2013;110:4357-62.

19. Beurskens R, Bock O. Age-related deficits of dual-task walking: a review. Neural Plast. 2012;2012:131608.

20. Zollig J, Eschen A. Measuring compensation and its plasticity across the lifespan. Restor Neurol Neurosci. 2009;27:421-33.

21. Takeuchi H, Kawashima R. Effects of processing speed training on cognitive functions and neural systems. Rev Neurosci. 2012;23:289-301.

22. Amdam GV. Social context, stress, and plasticity of aging. Aging Cell. 2011;10:18-27.

23. Wingfield A, Grossman M. Language and the aging brain: patterns of neural compensation revealed by functional brain imaging. J Neurophysiol. 2006;96:2830-9.

24. Robbins J, Hamilton JW, Lof GL, Kempster GB. Oropharyngeal swallowing in normal adults of different ages. Gastroenterology. 1992;103:823-9.

25. Malmgren LT, Fisher PJ, Bookman LM, Uno T. Age-related changes in muscle fiber types in the human thyroarytenoid muscle: an immunohistochemical and stereological study using confocal laser scanning microscopy. Otolaryngol Head Neck Surg. 1999;121:441-51.

26. Nakayama M. Histological study on aging changes in the human tongue. Nihon Jibiinkoka Gakkai Kaiho. 1991;94:541-55.

27. Bassler R. Histopathology of different types of atrophy of the human tongue. Pathol Res Pract. 1987;182:87-97. 
28. Smith CH, Logemann JA, Burghardt WR, Zecker SG, Rademaker AW. Oral and oropharyngeal perceptions of fluid viscosity across the age span. Dysphagia. 2006;21:209-17.

29. Wohlert AB. Reflex responses of lip muscles in young and older women. J Speech Hear Res. 1996;39:578-89.

30. Calhoun KH, Gibson B, Hartley L, Minton J, Hokanson JA. Age-related changes in oral sensation. Laryngoscope. 1992; 102:109-16.

31. Bartoshuk LM. Taste. Robust across the age span? Ann N Y Acad Sci. 1989;561:65-75.

32. Johnson KO, Phillips JR. Tactile spatial resolution. I. Two-point discrimination, gap detection, grating resolution, and letter recognition. J Neurophysiol. 1981;46:1177-92.

33. Cook IJ, Weltman MD, Wallace K, Shaw DW, McKay E, Smart $\mathrm{RC}$, et al. Influence of aging on oral-pharyngeal bolus transit and clearance during swallowing: scintigraphic study. Am J Physiol. 1994;266:G972-7.

34. Dejaeger E, Pelemans W. Swallowing and the duration of the hyoid movement in normal adults of different ages. Aging. 1996;8:130-4.

35. Logemann JA, Pauloski BR, Rademaker AW, Kahrilas PJ. Oropharyngeal swallow in younger and older women: videofluoroscopic analysis. J Speech Lang Hear Res. 2002;45:434-45.

36. Tracy JF, Logemann JA, Kahrilas PJ, Jacob P, Kobara M, Krugler C. Preliminary observations on the effects of age on oropharyngeal deglutition. Dysphagia. 1989;4:90-4.

37. Leow LP, Huckabee ML, Anderson T, Beckert L. The impact of dysphagia on quality of life in ageing and Parkinson's disease as measured by the swallowing quality of life (SWAL-QOL) questionnaire. Dysphagia. 2010;25:216-20.

38. Humbert IA, Fitzgerald ME, McLaren DG, Johnson S, Porcaro E, Kosmatka K, et al. Neurophysiology of swallowing: effects of age and bolus type. Neuroimage. 2009;44:982-91.

39. Humbert IA, McLaren DG, Malandraki G, Johnson SC, Robbins J. Swallowing intentional off-state in aging and Alzheimer's disease: preliminary study. J Alzheimers Dis. 2011;26:347-54.

40. Malandraki GA, Perlman AL, Karampinos DC, Sutton BP. Reduced somatosensory activations in swallowing with age. Hum Brain Mapp. 2011;32:730-43.

41. Malandraki GA, Sutton BP, Perlman AL, Karampinos DC. Agerelated differences in laterality of cortical activations in swallowing. Dysphagia. 2010;25:238-49.

42. Martin R, Barr A, MacIntosh B, Smith R, Stevens T, Taves D, et al. Cerebral cortical processing of swallowing in older adults. Exp Brain Res. 2007;176:12-22.

43. Knoflach M, Matosevic B, Rucker M, Furtner M, Mair A, Wille $\mathrm{G}$, et al. Functional recovery after ischemic stroke-a matter of age: data from the Austrian Stroke Unit Registry. Neurology. 2012;78:279-85.

44. Jongbloed L. Prediction of function after stroke: a critical review. Stroke. 1986;17:765-76.

45. Bagg S, Pombo AP, Hopman W. Effect of age on functional outcomes after stroke rehabilitation. Stroke. 2002;33:179-85.

46. Baron EM, Soliman AM, Gaughan JP, Simpson L, Young WF. Dysphagia, hoarseness, and unilateral true vocal fold motion impairment following anterior cervical discectomy and fusion. Ann Otol Rhinol Laryngol. 2003;112:921-6.

47. Nakajima M, Inatomi Y, Yonehara T, Hashimoto Y, Hirano T. Acquisition of oral intake in severely dysphagic patients with acute stroke: a single-center, observational study involving a database of 4972 consecutive stroke patients. J Neurol Sci. 2012;323:56-60.

48. Dy RC, Kumar R, Scremin OU. Clinical outcomes of dysphagia in elderly patients with cerebrovascular accident. J Neurol Rehabil. 1996;10:217-22.

49. McMicken BL, Muzzy CL. Prognostic indicators of functional outcomes in first time documented acute stroke patients following standard dysphagia treatment. Disabil Rehabil. 2009;31:

2196-203.

50. Allred RP, Jones TA. Experience-a double edged sword for restorative neural plasticity after brain damage. Future Neurol. 2008;3:189-98.

51. Kwakkel G, Kollen B, Lindeman E. Understanding the pattern of functional recovery after stroke: facts and theories. Restor Neurol Neurosci. 2004;22:281-99.

52. Whishaw IQ. Loss of the innate cortical engram for action patterns used in skilled reaching and the development of behavioral compensation following motor cortex lesions in the rat. Neuropharmacology. 2000;39:788-805.

53. Jones TA, Schallert T. Use-dependent growth of pyramidal neurons after neocortical damage. J Neurosci. 1994;14:2140-52.

54. Kahrilas PJ, Logemann JA, Gibbons P. Food intake by maneuver; an extreme compensation for impaired swallowing. Dysphagia. 1992;7:155-9.

55. Harding A, Grunwell P. Active versus passive cleft-type speech characteristics. Int J Lang Commun Disord. 1998;33:329-52.

56. Dorf DS, Curtin JW. Early cleft palate repair and speech outcome. Plast Reconstr Surg. 1982;70:74-81.

57. Hamdy S, Aziz Q, Rothwell JC, Power M, Singh KD, Nicholson DA, et al. Recovery of swallowing after dysphagic stroke relates to functional reorganization in the intact motor cortex. Gastroenterology. 1998;115:1104-12.

58. Teismann IK, Steinstraeter O, Warnecke T, Zimmermann J, Ringelstein EB, Pantev C, et al. Cortical recovery of swallowing function in wound botulism. BMC Neurol. 2008;8:13.

59. Fujiu M, Logemann J, Pauloski B. Increased postoperative posterior pharyngeal wall movement in patients with anterior oral cancer: preliminary findings and possible implications for treatment. Am J Speech Lang Pathol. 1995;4:24-30.

60. Fujiu M, Logemann JA. Effect of a tongue-holding maneuver on posterior pharyngeal wall movement during deglutition. Am J Speech Lang Pathol. 1996;5:23-30.

61. Nudo RJ. Adaptive plasticity in motor cortex: implications for rehabilitation after brain injury. J Rehabil Med. 2003;41:7-10.

62. Nudo RJ. Mechanisms for recovery of motor function following cortical damage. Curr Opin Neurobiol. 2006;16:638-44.

63. Bartolome G, Neumann S. Swallowing therapy in patients with neurological disorders causing cricopharyngeal dysfunction. Dysphagia. 1993;8:146-9.

64. Bryant M. Biofeedback in the treatment of a selected dysphagic patient. Dysphagia. 1991;6:140-4.

65. Carroll WR, Locher JL, Canon CL, Bohannon IA, McColloch NL, Magnuson JS. Pretreatment swallowing exercises improve swallow function after chemoradiation. Laryngoscope. 2008; 118:39-43.

66. Crary MA. A direct intervention program for chronic neurogenic dysphagia secondary to brainstem stroke. Dysphagia. 1995;10:6-18.

67. Huckabee ML, Cannito MP. Outcomes of swallowing rehabilitation in chronic brainstem dysphagia: A retrospective evaluation. Dysphagia. 1999;14:93-109.

68. Kotz T, Federman AD, Kao J, Milman L, Packer S, LopezPrieto C, et al. Prophylactic swallowing exercises in patients with head and neck cancer undergoing chemoradiation: a randomized trial. Arch Otolaryngol Head Neck Surg. 2012;138: 376-82.

69. Kulbersh BD, Rosenthal EL, McGrew BM, Duncan RD, McColloch NL, Carroll WR, et al. Pretreatment, preoperative swallowing exercises may improve dysphagia quality of life. Laryngoscope. 2006;116:883-6.

70. Nagaya M, Kachi T, Yamada T. Effect of swallowing training on swallowing disorders in Parkinson's disease. Scand J Rehabil Med. 2000;32:11-5. 
71. Neumann S, Bartolome G, Buchholz D, Prosiegel M. Swallowing therapy of neurologic patients: correlation of outcome with pretreatment variables and therapeutic methods. Dysphagia. 1995;10:1-5.

72. McCullough GH, Kamarunas E, Mann GC, Schmidley JW, Robbins JA, Crary MA. Effects of Mendelsohn maneuver on measures of swallowing duration post stroke. Top Stroke Rehabil. 2012;19:234-43.

73. McCullough GH, Kim Y. Effects of the Mendelsohn maneuver on extent of hyoid movement and UES opening post-stroke. Dysphagia. 2013.

74. Oh JC, Park JW, Cha TH, Woo HS, Kim DK. Exercise using tongue-holding swallow does not improve swallowing function in normal subjects. J Oral Rehabil. 2012;39:364-9.

75. Humbert IA, Christopherson H, Lokhande A, German R, Gonzalez-Fernandez M, Celnik P. Human hyolaryngeal movements show adaptive motor learning during swallowing. Dysphagia. 2013;28:139-45.

76. Humbert IA, Lokhande A, Christopherson H, German R, Stone A. Adaptation of swallowing hyo-laryngeal kinematics is distinct in oral vs. pharyngeal sensory processing. J Appl Physiol. 2012;112:1698-705.

77. Rose DJ, Christina RW. A multilevel approach to the study of motor control and learning. 2nd ed. San Francisco: Benjamin Cummings; 2006.

78. Salmoni AW, Schmidt RA, Walter CB. Knowledge of results and motor learning: a review and critical reappraisal. Psychol Bull. 1984;95:355-86.

79. Wahab NA, Jones RD, Huckabee ML. Effects of olfactory and gustatory stimuli on neural excitability for swallowing. Physiol Behav. 2010;101:568-75.

80. Doeltgen SH, Dalrymple-Alford J, Ridding MC, Huckabee ML. Differential effects of neuromuscular electrical stimulation parameters on submental motor-evoked potentials. Neurorehabil Neural Repair. 2010;24:519-27.

81. Fraser C, Power M, Hamdy S, Rothwell J, Hobday D, Hollander I, et al. Driving plasticity in human adult motor cortex is associated with improved motor function after brain injury. Neuron. 2002;34:831-40.

82. Fraser C, Rothwell J, Power M, Hobson A, Thompson D, Hamdy S. Differential changes in human pharyngoesophageal motor excitability induced by swallowing, pharyngeal stimulation, and anesthesia. Am J Physiol Gastrointest Liver Physiol. 2003;285:G137-44.

83. Gow D, Rothwell J, Hobson A, Thompson D, Hamdy S. Induction of long-term plasticity in human swallowing motor cortex following repetitive cortical stimulation. Clin Neurophysiol. 2004;115:1044-51.

84. Jefferson S, Mistry S, Michou E, Singh S, Rothwell JC, Hamdy $S$. Reversal of a virtual lesion in human pharyngeal motor cortex by high frequency contralesional brain stimulation. Gastroenterology 2009;137:841-49, 849, e841.

85. Jefferson S, Mistry S, Singh S, Rothwell J, Hamdy S. Characterizing the application of transcranial direct current stimulation in human pharyngeal motor cortex. Am J Physiol Gastrointest Liver Physiol. 2009;297:G1035-40.

86. Mistry S, Rothwell JC, Thompson DG, Hamdy S. Modulation of human cortical swallowing motor pathways after pleasant and aversive taste stimuli. Am J Physiol Gastrointest Liver Physiol. 2006;291:G666-71.

87. Mistry S, Verin E, Singh S, Jefferson S, Rothwell JC, Thompson DG, et al. Unilateral suppression of pharyngeal motor cortex to repetitive transcranial magnetic stimulation reveals functional asymmetry in the hemispheric projections to human swallowing. J Physiol. 2007;585:525-38.
88. Power M, Fraser C, Hobson A, Rothwell JC, Mistry S, Nicholson DA, et al. Changes in pharyngeal corticobulbar excitability and swallowing behavior after oral stimulation. Am J Physiol Gastrointest Liver Physiol. 2004;286:G45-50.

89. Robbins J, Kays SA, Gangnon RE, Hind JA, Hewitt AL, Gentry LR, et al. The effects of lingual exercise in stroke patients with dysphagia. Arch Phys Med Rehabil. 2007;88:150-8.

90. Yeates EM, Molfenter SM, Steele CM. Improvements in tongue strength and pressure-generation precision following a tonguepressure training protocol in older individuals with dysphagia: three case reports. Clin Interv Aging. 2008;3:735-47.

91. Baijens LW, Speyer R, Passos VL, Pilz W, Roodenburg N, Clave $P$. The effect of surface electrical stimulation on swallowing in dysphagic Parkinson patients. Dysphagia. 2012;27:528-37.

92. Heck FM, Doeltgen SH, Huckabee ML. Effects of submental neuromuscular electrical stimulation on pharyngeal pressure generation. Arch Phys Med Rehabil. 2012;93:2000-7.

93. Humbert IA, Poletto CJ, Saxon KG, Kearney PR, Crujido L, Wright-Harp W, et al. The effect of surface electrical stimulation on hyolaryngeal movement in normal individuals at rest and during swallowing. J Appl Physiol. 2006;101:1657-63.

94. Humbert IA, Poletto CJ, Saxon KG, Kearney PR, Ludlow CL. The effect of surface electrical stimulation on vocal fold position. Laryngoscope. 2008;118:14-9.

95. Ludlow CL, Humbert I, Saxon K, Poletto C, Sonies B, Crujido L. Effects of surface electrical stimulation both at rest and during swallowing in chronic pharyngeal dysphagia. Dysphagia. 2007;22:1-10.

96. Kim J, Davenport P, Sapienza C. Effect of expiratory muscle strength training on elderly cough function. Arch Gerontol Geriatr. 2009;48:361-6.

97. Wheeler KM, Chiara T, Sapienza CM. Surface electromyographic activity of the submental muscles during swallow and expiratory pressure threshold training tasks. Dysphagia. 2007;22:108-16.

98. Wheeler-Hegland KM, Rosenbek JC, Sapienza CM. Submental sEMG and hyoid movement during Mendelsohn maneuver, effortful swallow, and expiratory muscle strength training. J Speech Lang Hear Res. 2008;51:1072-87.

99. Malandraki GA, Kaufman A, Hind J, Ennis S, Gangnon R, Waclawik A, et al. The effects of lingual intervention in a patient with inclusion body myositis and Sjogren's syndrome: a longitudinal case study. Arch Phys Med Rehabil. 2012;93:1469-75.

100. Robbins J, Gangnon RE, Theis SM, Kays SA, Hewitt AL, Hind JA. The effects of lingual exercise on swallowing in older adults. J Am Geriatr Soc. 2005;53:1483-9.

101. Steele CM, Bailey GL, Molfenter SM, Yeates EM, Grace-Martin K. Pressure profile similarities between tongue resistance training tasks and liquid swallows. J Rehabil Res Dev. 2010;47:651-60.

102. Yoshida M, Groher ME, Crary MA, Mann GC, Akagawa Y. Comparison of surface electromyographic (sEMG) activity of submental muscles between the head lift and tongue press exercises as a therapeutic exercise for pharyngeal dysphagia. Gerodontology. 2007;24:111-6.

103. Bulow M, Speyer R, Baijens L, Woisard V, Ekberg O. Neuromuscular electrical stimulation (NMES) in stroke patients with oral and pharyngeal dysfunction. Dysphagia. 2008;23:302-9.

104. Carnaby-Mann GD, Crary MA. Adjunctive neuromuscular electrical stimulation for treatment-refractory dysphagia. Ann Otol Rhinol Laryngol. 2008;117:279-87.

105. Leelamanit V, Limsakul C, Geater A. Synchronized electrical stimulation in treating pharyngeal dysphagia. Laryngoscope. 2002;112:2204-10.

106. Lim KB, Lee HJ, Lim SS, Choi YI. Neuromuscular electrical and thermal-tactile stimulation for dysphagia caused by stroke: a randomized controlled trial. J Rehabil Med. 2009;41:174-8. 
107. Long YB, Wu XP. A randomized controlled trail of combination therapy of neuromuscular electrical stimulation and balloon dilatation in the treatment of radiation-induced dysphagia in nasopharyngeal carcinoma patients. Disabil Rehabil. 2013;35: 450-4.

108. Nam HS, Beom J, Oh BM, Han TR. Kinematic effects of hyolaryngeal electrical stimulation therapy on hyoid excursion and laryngeal elevation. Dysphagia. 2013.

109. Oh BM, Kim DY, Paik NJ. Recovery of swallowing function is accompanied by the expansion of the cortical map. Int $\mathbf{J}$ Neurosci. 2007;117:1215-27.

110. Park JW, Oh JC, Lee HJ, Park SJ, Yoon TS, Kwon BS. Effortful swallowing training coupled with electrical stimulation leads to an increase in hyoid elevation during swallowing. Dysphagia. 2009;24:296-301.

111. Restivo DA, Casabona A, Centonze D, Marchese-Ragona R, Maimone D, Pavone A. Pharyngeal electrical stimulation for dysphagia associated with multiple sclerosis: a pilot study. Brain Stimul. 2013;6:418-23.

112. Shaw GY, Sechtem PR, Searl J, Keller K, Rawi TA, Dowdy E. Transcutaneous neuromuscular electrical stimulation (VitalStim) curative therapy for severe dysphagia: myth or reality? Ann Otol Rhinol Laryngol. 2007;116:36-44.

113. Suiter DM, Leder SB, Ruark JL. Effects of neuromuscular electrical stimulation on submental muscle activity. Dysphagia. 2006;21:56-60.

114. Pitts T, Bolser D, Rosenbek J, Troche M, Okun MS, Sapienza C. Impact of expiratory muscle strength training on voluntary cough and swallow function in Parkinson disease. Chest. 2009;135:1301-8.

115. Troche MS, Okun MS, Rosenbek JC, Musson N, Fernandez HH, Rodriguez R, et al. Aspiration and swallowing in Parkinson disease and rehabilitation with EMST: a randomized trial. Neurology. 2010;75:1912-9.

116. Lazarus C, Logemann JA, Huang CF, Rademaker AW. Effects of two types of tongue strengthening exercises in young normals. Folia Phoniatr Logop. 2003;55:199-205.

117. Crary MA, Carnaby GD, LaGorio LA, Carvajal PJ. Functional and physiological outcomes from an exercise-based dysphagia therapy: a pilot investigation of the McNeill dysphagia therapy program. Arch Phys Med Rehabil. 2012;93:1173-8.

118. Lan Y, Ohkubo M, Berretin-Felix G, Sia I, Carnaby-Mann GD, Crary MA. Normalization of temporal aspects of swallowing physiology after the McNeill dysphagia therapy program. Ann Otol Rhinol Laryngol. 2012;121:525-32.

119. Barikroo A, Lam PM. Comparing the effects of rehabilitation swallowing therapy vs. functional neuromuscular electrical stimulation therapy in an encephalitis patient: a case study. Dysphagia. 2011;26:418-23.

120. Beom J, Kim SJ, Han TR. Electrical stimulation of the suprahyoid muscles in brain-injured patients with dysphagia: a pilot study. Ann Rehabil Med. 2011;35:322-7.

121. Blumenfeld L, Hahn Y, Lepage A, Leonard R, Belafsky PC. Transcutaneous electrical stimulation versus traditional dysphagia therapy: a nonconcurrent cohort study. Otolaryngol Head Neck Surg. 2006;135:754-7.

122. Bogaardt H, van Dam D, Wever NM, Bruggeman CE, Koops J, Fokkens WJ. Use of neuromuscular electrostimulation in the treatment of dysphagia in patients with multiple sclerosis. Ann Otol Rhinol Laryngol. 2009;118:241-6.

123. Freed ML, Freed L, Chatburn RL, Christian M. Electrical stimulation for swallowing disorders caused by stroke. Respir Care. 2001;46:466-74.

124. Gallas S, Marie JP, Leroi AM, Verin E. Sensory transcutaneous electrical stimulation improves post-stroke dysphagic patients. Dysphagia. 2010;25:291-7.
125. Heijnen BJ, Speyer R, Baijens LW, Bogaardt HC. Neuromuscular electrical stimulation versus traditional therapy in patients with Parkinson's disease and oropharyngeal dysphagia: effects on quality of life. Dysphagia. 2012;27:336-45.

126. Kiger M, Brown CS, Watkins L. Dysphagia management: an analysis of patient outcomes using VitalStim therapy compared to traditional swallow therapy. Dysphagia. 2006;21:243-53.

127. Kushner DS, Peters K, Eroglu ST, Perless-Carroll M, JohnsonGreene D. Neuromuscular electrical stimulation efficacy in acute stroke feeding tube-dependent dysphagia during inpatient rehabilitation. Am J Phys Med Rehabil. 2013;92:486-95.

128. Permsirivanich W, Tipchatyotin S, Wongchai M, Leelamanit V, Setthawatcharawanich S, Sathirapanya P, et al. Comparing the effects of rehabilitation swallowing therapy vs. neuromuscular electrical stimulation therapy among stroke patients with persistent pharyngeal dysphagia: a randomized controlled study. J Med Assoc Thai. 2009;92:259-65.

129. Ryu JS, Kang JY, Park JY, Nam SY, Choi SH, Roh JL, et al. The effect of electrical stimulation therapy on dysphagia following treatment for head and neck cancer. Oral Oncol. 2009; 45:665-8.

130. Sun SF, Hsu CW, Lin HS, Sun HP, Chang PH, Hsieh WL, et al. Combined neuromuscular electrical stimulation (NMES) with fiberoptic endoscopic evaluation of swallowing (FEES) and traditional swallowing rehabilitation in the treatment of strokerelated dysphagia. Dysphagia. 2013.

131. Carnaby-Mann GD, Crary MA. McNeill dysphagia therapy program: a case-control study. Arch Phys Med Rehabil. 2010;91:743-9.

132. Bulow M, Olsson R, Ekberg O. Videomanometric analysis of supraglottic swallow, effortful swallow, and chin tuck in healthy volunteers. Dysphagia. 1999;14:67-72.

133. Garcia JM. Unexpected consequence of effortful swallowing: case study report. J Med Speech Lang Pathol. 2004;12:59-66.

134. Steele CM, Huckabee ML. The influence of orolingual pressure on the timing of pharyngeal pressure events. Dysphagia. 2007;22:30-6.

135. Bulow M, Olsson R, Ekberg O. Videomanometric analysis of supraglottic swallow, effortful swallow, and chin tuck in patients with pharyngeal dysfunction. Dysphagia. 2001;16:190-5.

136. Bulow M, Olsson R, Ekberg O. Supraglottic swallow, effortful swallow, and chin tuck did not alter hypopharyngeal intrabolus pressure in patients with pharyngeal dysfunction. Dysphagia. 2002;17:197-201.

137. Hind JA, Nicosia MA, Roecker EB, Carnes ML, Robbins J. Comparison of effortful and noneffortful swallows in healthy middle-aged and older adults. Arch Phys Med Rehabil. 2001;82: 1661-5.

138. Hiss SG, Huckabee ML. Timing of pharyngeal and upper esophageal sphincter pressures as a function of normal and effortful swallowing in young healthy adults. Dysphagia. 2005;20:149-56.

139. Hoffman MR, Mielens JD, Ciucci MR, Jones CA, Jiang JJ, McCulloch TM. High-resolution manometry of pharyngeal swallow pressure events associated with effortful swallow and the Mendelsohn maneuver. Dysphagia. 2012;27:418-26.

140. Huckabee ML, Butler SG, Barclay M, Jit S. Submental surface electromyographic measurement and pharyngeal pressures during normal and effortful swallowing. Arch Phys Med Rehabil. 2005;86:2144-9.

141. Huckabee ML, Steele CM. An analysis of lingual contribution to submental surface electromyographic measures and pharyngeal pressure during effortful swallow. Arch Phys Med Rehabil. 2006;87:1067-72.

142. Lazarus C, Logemann JA, Song CW, Rademaker AW, Kahrilas PJ. Effects of voluntary maneuvers on tongue base function for swallowing. Folia Phoniatr Logop. 2002;54:171-6. 
143. Lever TE, Cox KT, Holbert D, Shahrier M, Hough M, KelleySalamon K. The effect of an effortful swallow on the normal adult esophagus. Dysphagia. 2007;22:312-25.

144. Nekl CG, Lintzenich CR, Leng X, Lever T, Butler SG. Effects of effortful swallow on esophageal function in healthy adults. Neurogastroenterol Motil. 2012;24:252-256, e107-258.

145. Ohmae Y, Sugiura M, Matumura Y, editors. Role of anterior tongue as an anchor during swallow. In: Proceedings of 11th world congress for bronchology (WCB)/11th world congress for bronchoesophagology (WCBE); 2000, Yokohama, Japan.

146. Pouderoux P, Kahrilas PJ. Deglutitive tongue force modulation by volition, volume, and viscosity in humans. Gastroenterology. 1995;108:1418-26.

147. Regan J, Walshe M, Rommel N, McMahon BP. A new evaluation of the upper esophageal sphincter using the functional lumen imaging probe: a preliminary report. Dis Esophagus. 2013;26:117-23.

148. Takasaki K, Umeki H, Hara M, Kumagami H, Takahashi H. Influence of effortful swallow on pharyngeal pressure: evaluation using a high-resolution manometry. Otolaryngol Head Neck Surg. 2011;144:16-20.

149. Witte U, Huckabee ML, Doeltgen SH, Gumbley F, Robb M. The effect of effortful swallow on pharyngeal manometric measurements during saliva and water swallowing in healthy participants. Arch Phys Med Rehabil. 2008;89:822-8.

150. Yeates EM, Steele CM, Pelletier CA. Tongue pressure and submental surface electromyography measures during noneffortful and effortful saliva swallows in healthy women. Am J Speech Lang Pathol. 2010;19:274-81.

151. Boden K, Hallgren A, Witt Hedstrom H. Effects of three different swallow maneuvers analyzed by videomanometry. Acta Radiol. 2006;47:628-33.

152. Ding R, Larson CR, Logemann JA, Rademaker AW. Surface electromyographic and electroglottographic studies in normal subjects under two swallow conditions: normal and during the Mendelsohn manuever. Dysphagia. 2002;17:1-12.

153. Fukuoka T, Ono T, Hori K, Tamine KI, Nozaki S, Shimada K, et al. Effect of the effortful swallow and the Mendelsohn maneuver on tongue pressure production against the hard palate. Dysphagia. 2013.

154. Kahrilas PJ, Logemann JA, Krugler C, Flanagan E. Volitional augmentation of upper esophageal sphincter opening during swallowing. Am J Physiol. 1991;260:G450-6.

155. Lazarus C, Logemann JA, Gibbons P. Effects of maneuvers on swallowing function in a dysphagic oral cancer patient. Head Neck. 1993;15:419-24.

156. Miller JL, Watkin KL. Lateral pharyngeal wall motion during swallowing using real time ultrasound. Dysphagia. 1997;12: 125-32.

157. Pearson WG Jr, Hindson DF, Langmore SE, Zumwalt AC. Evaluating swallowing muscles essential for hyolaryngeal elevation by using muscle functional magnetic resonance imaging. Int J Radiat Oncol Biol Phys. 2013;85:735-40.

158. Doeltgen SH, Macrae P, Huckabee ML. Pharyngeal pressure generation during tongue-hold swallows across age groups. Am J Speech Lang Pathol. 2011;20:124-30.

159. Doeltgen SH, Witte U, Gumbley F, Huckabee ML. Evaluation of manometric measures during tongue-hold swallows. Am J Speech Lang Pathol. 2009;18:65-73.

160. Umeki H, Takasaki K, Enatsu K, Tanaka F, Kumagami H, Takahashi $\mathrm{H}$. Effects of a tongue-holding maneuver during swallowing evaluated by high-resolution manometry. Otolaryngol Head Neck Surg. 2009;141:119-22.
161. Alfonso M, Ferdjallah M, Shaker R, Wertsch J. Electrophysiologic validation of deglutitive UES opening head lift exercise. Gastroenterology. 1998;114:A711.

162. Ferdjallah M, Wertsch JJ, Shaker R. Spectral analysis of surface electromyography (EMG) of upper esophageal sphincter-opening muscles during head lift exercise. J Rehabil Res Dev. 2000;37:335-40.

163. Jurell KC, Shaker R, Mazur A, Haig AJ, Wertsch J. Effect of exercise on upper esophageal sphincter opening muscles: a spectral analysis. Gastroenterology. 1997;112:A757.

164. Mepani R, Antonik S, Massey B, Kern M, Logemann J, Pauloski $\mathrm{B}$, et al. Augmentation of deglutitive thyrohyoid muscle shortening by the Shaker exercise. Dysphagia. 2009;24:26-31.

165. White KT, Easterling C, Roberts N, Wertsch J, Shaker R. Fatigue analysis before and after shaker exercise: physiologic tool for exercise design. Dysphagia. 2008;23:385-91.

166. Easterling C. Does an exercise aimed at improving swallow function have an effect on vocal function in the healthy elderly? Dysphagia. 2008;23:317-26.

167. Easterling C, Grande B, Kern M, Sears K, Shaker R. Attaining and maintaining isometric and isokinetic goals of the Shaker exercise. Dysphagia. 2005;20:133-8.

168. Logemann JA, Rademaker A, Pauloski BR, Kelly A, StanglMcBreen C, Antinoja J, et al. A randomized study comparing the Shaker exercise with traditional therapy: a preliminary study. Dysphagia. 2009;24:403-11.

169. Shaker R, Easterling C, Kern M, Nitschke T, Massey B, Daniels $\mathrm{S}$, et al. Rehabilitation of swallowing by exercise in tube-fed patients with pharyngeal dysphagia secondary to abnormal UES opening. Gastroenterology. 2002;122:1314-21.

170. Shaker R, Kern M, Bardan E, Taylor A, Stewart ET, Hoffmann $\mathrm{RG}$, et al. Augmentation of deglutitive upper esophageal sphincter opening in the elderly by exercise. Am J Physiol. 1997;272: G1518-22.

171. Malandraki GA, Johnson S, Robbins J. Functional MRI of swallowing: from neurophysiology to neuroplasticity. Head Neck. 2011;33(Suppl 1):S14-20.

172. Humbert IA, Joel S. Tactile, gustatory, and visual biofeedback stimuli modulate neural substrates of deglutition. Neuroimage. 2012;59:1485-90.

173. Khedr EM, Abo-Elfetoh N, Rothwell JC. Treatment of poststroke dysphagia with repetitive transcranial magnetic stimulation. Acta Neurol Scand. 2009;119:155-61.

174. Gow D, Hobson AR, Furlong P, Hamdy S. Characterising the central mechanisms of sensory modulation in human swallowing motor cortex. Clin Neurophysiol. 2004;115:2382-90.

175. Peck KK, Branski RC, Lazarus C, Cody V, Kraus D, Haupage S, et al. Cortical activation during swallowing rehabilitation maneuvers: a functional MRI study of healthy controls. Laryngoscope. 2010;120:2153-9.

176. Teismann IK, Steinstraeter O, Stoeckigt K, Suntrup S, Wollbrink A, Pantev C, et al. Functional oropharyngeal sensory disruption interferes with the cortical control of swallowing. BMC Neurosci. 2007;8:62.

177. Teismann IK, Steinstrater O, Warnecke T, Suntrup S, Ringelstein EB, Pantev $\mathrm{C}$, et al. Tactile thermal oral stimulation increases the cortical representation of swallowing. BMC Neurosci. 2009; 10:71.

178. Kleim JA, Jones TA. Principles of experience-dependent neural plasticity: implications for rehabilitation after brain damage. J Speech Lang Hear Res. 2008;51:S225-39.

179. Shaker R, Ren J, Zamir Z, Sarna A, Liu J, Sui Z. Effect of aging, position, and temperature on the threshold volume triggering pharyngeal swallows. Gastroenterology. 1994;107:396-402. 